\title{
Tuning the electronic properties of graphene-graphitic carbon nitride heterostructures and heterojunctions by using an electric field
}

\author{
A. Bafekry $\odot^{1, *}$ and M. Neek-Amal $\odot^{2, \dagger}$ \\ ${ }^{1}$ Department of physics, University of Guilan, 41335-1914 Rasht, Iran \\ and Department of Physics, University of Antwerp, Groenenborgerlaan 171, B-2020 Antwerp, Belgium \\ ${ }^{2}$ Department of Physics, Shahid Rajaee University, 16875-163 Lavizan, Tehran, Iran
}

(Received 4 November 2019; revised manuscript received 7 January 2020; accepted 31 January 2020; published 24 February 2020)

\begin{abstract}
Integration of graphene-based two-dimensional materials is essential for nanoelectronics applications. Using density-functional theory, we systematically investigate the electronic properties of vertically stacked graphenegraphitic carbon nitrides (GE/GCN). We also studied the covalently lateral stitched graphene-graphitic carbon nitrides (GE-GCN heterojunctions). The effects of perpendicular electric field on the electronic properties of six different heterostructures, i.e., (i) one layer of GE on top of a layer of $\mathrm{C}_{n} \mathrm{~N}_{m}$ with $(n, m)=(3,1),(3,4)$, and $(4,3)$ and (ii) three heterostructures $\mathrm{C}_{n} \mathrm{~N}_{m} / \mathrm{C}_{n^{\prime}} \mathrm{N}_{m^{\prime}}$, where $(n, m) \neq\left(n^{\prime}, m^{\prime}\right)$ are elucidated. The most important calculated features are (i) the systems $\mathrm{GE} / \mathrm{C}_{3} \mathrm{~N}_{4}, \mathrm{C}_{3} \mathrm{~N} / \mathrm{C}_{3} \mathrm{~N}_{4}, \mathrm{GE}-\mathrm{C}_{3} \mathrm{~N}, \mathrm{GE}-\mathrm{C}_{4} \mathrm{~N}_{3}$, and $\mathrm{C}_{3} \mathrm{~N}-\mathrm{C}_{3} \mathrm{~N}_{4}$ exhibit semiconducting characteristics having small band gaps of $\Delta_{0}=20,250,100,100,80 \mathrm{meV}$, respectively while (ii) the systems $\mathrm{GE} / \mathrm{C}_{4} \mathrm{~N}_{3}, \mathrm{C}_{3} \mathrm{~N} / \mathrm{C}_{4} \mathrm{~N}_{3}$, and $\mathrm{C}_{3} \mathrm{~N}-\mathrm{C}_{4} \mathrm{~N}_{3}$ show ferromagnetic-metallic properties. In particular, we found that, in semiconducting heterostructures, the band gap increases nontrivially with increasing the absolute value of the applied perpendicular electric field. This work is useful for designing heterojunctions and heterostructures made of graphene and other two-dimensional materials such as those proposed in recent experiments [X. Liu and M. C. Hersam Sci. Adv. 5, 6444 (2019)].
\end{abstract}

DOI: 10.1103/PhysRevB.101.085417

\section{INTRODUCTION}

Two-dimensional graphitic carbon nitrides (2D-GCNs) reveal unusual properties and provide potential applications in photocatalysis, heterogeneous catalysis, and fuel cells $[1,2]$. For example, polyaniline $\left(\mathrm{C}_{3} \mathrm{~N}\right)$ has been fabricated [3] and exhibits amazing electronic and mechanical properties [4,5]. Also, $\mathrm{C}_{3} \mathrm{~N}_{4}$ as a potential photocatalyst for water splitting $[6,7]$ has electronic and magnetic properties which are drastically modified by injecting a hole by substituting an $\mathrm{N}$ atom with a $\mathrm{C}$ atom. Also, the $\mathrm{C}_{4} \mathrm{~N}_{3}$ was successfully synthesized [8] and it was identified that it is a half metal [9]. On the other hand, the van der Waals (vdW) heterostructures (HTSs) such as graphene/ $\mathrm{MoS}_{2}$ [7,10-12], graphene/hexagonal boron nitride (GE/h-BN) [13-15], graphene/silicene [16,17], graphene/g- $\mathrm{C}_{3} \mathrm{~N}_{4}$ [18], and graphene/phosphorene [19] have been widely studied experimentally and theoretically. They can preserve the intrinsic electronic properties of the dissimilar two-dimensional material (2DM) and create particularly advantageous electronic properties. Recently, a HTS made of graphene (GE) and $2 \mathrm{D}-\mathrm{GCN}\left(\mathrm{GE} / \mathrm{C}_{3} \mathrm{~N}\right)$ was proposed by Wang et al. [20]. The proposed $\mathrm{C}_{3} \mathrm{~N} /$ graphene exhibits a metallic behavior and is stable under the applied large strains of about $10 \%$. Recently, the lateral and vertical integration of borophene with GE was reported [1]. It was found that boron intercalation under GE results in rotationally commensurate vertical HTSs. Moreover, the fabricated red phosphorus GCN

\footnotetext{
*Bafekry.asad@gmail.com

${ }^{\dagger}$ Corresponding author: mehdi.neekamal@gmail.com
}

(EPh-GCN) HTS supercapacitor by Ansari et al. [21] displays a high capacitance of $465 \mathrm{~F} / \mathrm{g}$ and excellent cyclic stability. The photocatalyitic behavior of RPh-GCN HTSs was found to be due to narrow band-gap energy, capacitive behavior, and high nitrogen content. Moreover, using ab initio simulations, it was found that the metal-free half-metallic behavior in $\mathrm{C}_{4} \mathrm{~N}_{3}$ can be preserved when it is put on a hexagonal boron nitride (h-BN) layer [22].

Although 2DMs hold great potential for a wide range of applications, it is necessary to modulate their intrinsic properties. In the past few years, several approaches have been developed to modify the electronic properties of $2 \mathrm{DMs}$, such as substitutional doping, defect engineering, surface functionalization by adatoms, applying electric field, and strain engineering [23-34].

Here, we report on the integration of GCNs with graphene. Using $a b$ initio calculations, we studied the electronic properties of six HTSs and six heterojunctions (HTJs) made of graphene and GCNs. The difference between the lattice parameter of GE and a typical $2 \mathrm{D}-\mathrm{GCN}$ is smaller than $4 \%$. Therefore, $a b$ initio modeling and simulations on these systems become feasible. The effects of perpendicular electric field on the electronic structure and band gap of HTSs are explored. The results show a wide variety of responses of HTSs to the electric field which are different from isolated GCN and emerging unique properties. In particular, in the studied semiconducting HTSs $\left(\mathrm{GE} / \mathrm{C}_{n} \mathrm{~N}_{m}\right)$, the band gap increases nontrivially with increasing the absolute value of applied perpendicular electric field. Furthermore, by analyzing charge distribution along the contact lines of HTJs, we discovered 
TABLE I. Calculated lattice constant and electronic structure of GE, $\mathrm{C}_{3} \mathrm{~N}, \mathrm{C}_{3} \mathrm{~N}_{4}$, and $\mathrm{C}_{4} \mathrm{~N}_{3}$ monolayers.

\begin{tabular}{lclcc}
\hline \hline Monolayer & Lattice constant $(\AA)$ & Electronic structure & Magnetic moment $\left(\mu_{B}\right)$ & Gap $(\mathrm{eV})$ \\
\hline $\mathrm{GE}$ & 2.46 & Semimetal (SM) & 0 & 0 \\
$\mathrm{C}_{3} \mathrm{~N}$ & 4.86 & Semiconductor $(\mathrm{SC})$ & 0 & 0.4 \\
$\mathrm{C}_{3} \mathrm{~N}_{4}$ & 4.74 & Semiconductor (SC) & 0 & 1.45 \\
$\mathrm{C}_{4} \mathrm{~N}_{3}$ & 4.81 & Half-metal (HM) & 1.0 & 2.21 \\
\hline \hline
\end{tabular}

that the HTJ made of $\mathrm{GE}$ and $\mathrm{C}_{3} \mathrm{~N}$ has the minimal mismatch at the contact line. This work explores underlying physics of functional materials (HTSs and HTJs) and corresponding band-gap engineering using external uniform electric field.

\section{COMPUTATIONAL METHOD}

First-principles calculations of energy and electronic structure are performed within the Perdew-Burke-Ernzerhof variant of the generalized gradient approximation [35] method as implemented in OPENMX package [36]. We used normconserving pseudopotentials [37] for carbon and nitrogen atoms. The wave functions are expanded by the linear combination of multiple pseudoatomic orbitals generated using a confinement scheme [36,38]. The $\boldsymbol{k}$ points for sampling over the Brillouin zone (BZ) integration were generated using the Monkhorst-Pack scheme [39]. After the convergence tests, we chose the cutoff 350 Ry for $G E, C_{3} N, C_{3} N$, and $C_{3} N_{4}$ monolayers. The latter causes the total energy to be converged below $1.0 \mathrm{meV} /$ atom. For all the studied HTSs and HTJs, we used a cutoff energy of $400 \mathrm{Ry}$. The geometries were fully relaxed until the force acting on each atom was less than $1 \mathrm{meV} / \AA$. With these parameters, the resulting structures are found to be sufficiently relaxed to obtain well-converged various properties in the next steps of the calculations. The BZ is sampled by a k-mesh grid of $23 \times 23 \times 1$ for primitive unit cell of monolayers and for different HTSs and HTJs, we used a k-mesh grid of $15 \times 15 \times 1$. In addition, the $\boldsymbol{k}$-mesh includes the high-symmetry points $(\Gamma, M, K)$ relevant to the hexagonal geometry. The grids of density of states (DOS) and partial density of states (PDOS) calculations are two times denser than that of for the self-consistent calculations. We also used Gaussian smearing width $0.2 \mathrm{eV}$ for the DOS and PDOS calculations. The 2D-GCNs are modeled as a periodic slab with a sufficiently large vacuum layer $(20 \AA)$ to avoid interaction between adjacent layers. To accurately describe the vdW interaction between layers of HTSs, we adopted the empirical correction method presented by Grimme (DFT-D2) [40], which is a reliable choice for describing the vdW interactions. To find the minimum energy configurations, we compared various AA with other AA and/or AB stacking for any given HTS.

\section{GRAPHENE-GRAPHITIC CARBON NITRIDE HETEROSTRUCTURES $\left(\mathrm{GE} / \mathrm{C}_{\boldsymbol{n}} \mathrm{N}_{m}\right)$}

We reviewed the geometrical and electronic properties of monolayers of GE, $\mathrm{C}_{3} \mathrm{~N}, \mathrm{C}_{3} \mathrm{~N}_{4}$, and $\mathrm{C}_{4} \mathrm{~N}_{3}$ in the Supplemental Material [41] (see Figs. S1 and S2 in Supplemental Material Sec. SI). Our results show that (i) $\mathrm{C}_{3} \mathrm{~N}$ is an indirect semiconductor with $0.4 \mathrm{eV}$ band gap, (ii) $\mathrm{C}_{3} \mathrm{~N}_{4}$ is a direct semiconductor with a band gap of $1.45 \mathrm{eV}$, (iii) $\mathrm{C}_{4} \mathrm{~N}_{3}$ exhibits half metallicity with a magnetic moment of $1 \mu_{B}$ per $1 \times 1$ unit cell, and (iV) GE is a semimetal with zero gap (see Supplemental Material Sec. SII). The obtained magnetic moment for monolayer $\mathrm{C}_{4} \mathrm{~N}_{3}$ is equal to that reported by $\mathrm{Du}$ et al. [9]. We listed the lattice constant and other electronic and magnetic properties of the above-mentioned monolayers in Table I.
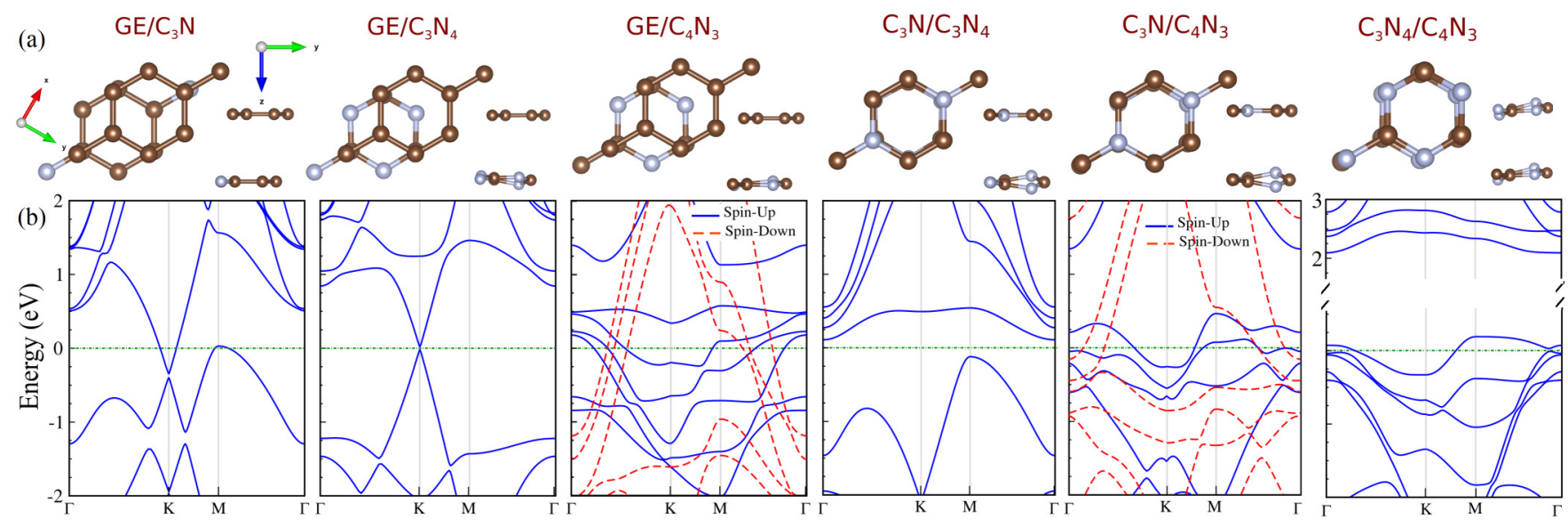

FIG. 1. (a) The most stable heterostructures and (b) the corresponding electronic band structures of GE/ $\mathrm{C}_{3} \mathrm{~N}, \mathrm{GE} / \mathrm{C}_{3} \mathrm{~N}_{4}, \mathrm{GE} / \mathrm{C}_{4} \mathrm{~N}_{3}$, $\mathrm{C}_{3} \mathrm{~N}_{4} / \mathrm{C}_{3} \mathrm{~N}, \mathrm{C}_{4} \mathrm{~N}_{3} / \mathrm{C}_{3} \mathrm{~N}$, and $\mathrm{C}_{3} \mathrm{~N}_{4} / \mathrm{C}_{4} \mathrm{~N}_{3}$ heterostructures. The brown atoms represent $\mathrm{C}$ and the blue atoms represent $\mathrm{N}$. The zero energy is set at Fermi level. 
TABLE II. The structural, electronic, and magnetic parameters of studied HTSs including lattice constant $a$, bond length between C-C atoms $\left(d_{C C}\right)$, the bond length between N-C atoms $\left(d_{N C}\right)$, the optimum interlayer distance between two layers $\left(z_{\text {eq }}\right)$, the buckling $(\delta)$ (i.e., the difference between the largest and smallest $z$ coordinates of $\mathrm{C}$ or $\mathrm{N}$ atoms in two layers) and the moiré period $(L)$ in $\AA$. The transition of the electronic state (TS) when two individual monolayers are placed on top of each other to form the corresponding HTS was indicated by an arrow $(\rightarrow)$ and transition state of HTS in the presence of an electric field of about $E=0.2 \mathrm{~V} \AA$ was indicated by two arrows ( $\Rightarrow$ ). The numbers outside (inside) the parenthesis is for the top (bottom) layer and the magnetic moment per unit cell is listed in the last column. The electronic states are specified as metal (M), ferromagnetic- metal (FM), half- metal (HM), and semiconductor (SC). The band gap of the HTSs ( $\Delta$ ) are also presented when $E=0$ and $E=0.2 \mathrm{VA}$.

\begin{tabular}{|c|c|c|c|c|c|c|c|c|c|c|}
\hline HTS & $a(\AA)$ & $d_{C C}(\AA)$ & $d_{N C}(\AA)$ & $z_{\mathrm{eq}}(\AA)$ & $\delta(\AA)$ & $\mathrm{TS}(E=0)$ & $\Delta(\mathrm{meV})$ & $\mathrm{TS}(E=0.2 \mathrm{~V} / \AA)$ & $M_{t o t}$ & $\mathrm{~L}(\AA)$ \\
\hline $\mathrm{GE} / \mathrm{C}_{3} \mathrm{~N}$ & 4.92 & $1.41(1.41)$ & $-(1.42)$ & 3.47 & $0(0)$ & $(\mathrm{SM}, \mathrm{SC}) \rightarrow \mathrm{M}$ & - & $\mathrm{M} \Rightarrow \mathrm{M}$ & 0 & 398 \\
\hline $\mathrm{GE} / \mathrm{C}_{3} \mathrm{~N}_{4}$ & 4.88 & $1.41(-)$ & $-(1.34)$ & 3.35 & $0(0.36)$ & $(\mathrm{SM}, \mathrm{SC}) \rightarrow \mathrm{SC}$ & 20 & $S C \Rightarrow \mathrm{SC}$ & 0 & 129 \\
\hline $\mathrm{GE} / \mathrm{C}_{4} \mathrm{~N}_{3}$ & 4.89 & $1.41(1.46)$ & $-(1.36)$ & 3.44 & $0(0.17)$ & $(\mathrm{SM}, \mathrm{HM}) \rightarrow \mathrm{FM}$ & - & - & 6.85 & 215 \\
\hline $\mathrm{C}_{3} \mathrm{~N} / \mathrm{C}_{3} \mathrm{~N}_{4}$ & 4.84 & $1.39(-)$ & $1.39(1.48,1.33)$ & 3.36 & $0(0.41)$ & $(\mathrm{SC}, \mathrm{SC}) \rightarrow \mathrm{SC}$ & 250 & $\mathrm{SC} \Rightarrow \mathrm{SC}$ & 0 & 191 \\
\hline $\mathrm{C}_{3} \mathrm{~N} / \mathrm{C}_{4} \mathrm{~N}_{3}$ & 4.85 & $1.40(1.45)$ & $1.39(1.34)$ & 3.30 & $0(0.33)$ & $(\mathrm{SC}, \mathrm{HM}) \rightarrow \mathrm{FM}$ & - & - & 1.4 & 467 \\
\hline $\mathrm{C}_{3} \mathrm{~N}_{4} / \mathrm{C}_{4} \mathrm{~N}_{3}$ & 4.82 & $-(1.44)$ & $1.34(1.35)$ & 3.50 & $0.36(0.41)$ & $(\mathrm{SC}, \mathrm{HM}) \rightarrow \mathrm{M}$ & - & - & 0 & 325 \\
\hline
\end{tabular}

The optimized monolayers of these systems are then used to make the corresponding HTSs and HTJs.

\section{A. The lattice structure of $\mathrm{GE} / \mathrm{C}_{n} \mathbf{N}_{m}$}

A $2 \times 2$ supercell of graphene and a unit cell of $\mathrm{C}_{3} \mathrm{~N}$, $\mathrm{C}_{3} \mathrm{~N}_{4}$, and $\mathrm{C}_{4} \mathrm{~N}_{3}$ are placed on top of each other to form six HTSs, which are shown in Fig. 1(a). The lattice mismatch $(\lambda)$ between top and bottom layer is defined as

$$
\lambda=\frac{\left|a_{T}-a_{B}\right|}{a_{B}} \times 100 \%,
$$

where $a_{T}$ and $a_{B}$ are the lattice constants of bottom $\left(\mathrm{C}_{n} \mathrm{~N}_{m}\right)$ and top layers, respectively. The optimized atomic structure (most stable configurations) of the studied HTSs are shown in Fig. 1(a). After optimization of single layers of GE and $\mathrm{C}_{n} \mathrm{~N}_{m}$ s, the lattice mismatch between $\mathrm{C}_{3} \mathrm{~N}, \mathrm{C}_{3} \mathrm{~N}_{4}, \mathrm{C}_{4} \mathrm{~N}_{3}$, and $\mathrm{GE}$ are found to be $1.22 \%, 3.66 \%$, and $2.23 \%$, respectively. Therefore, there is small distortion in the geometrical structure of these systems. The latter enabled us to perform extensive $a b$ initio calculations on the HTSs (see the Supplemental Material Fig. S5 for the size effects). Because of the nonzero $\lambda$, a moiré pattern appears even when GE and $\mathrm{C}_{n} \mathrm{~N}_{m}$ layers are not misaligned. The moiré period $(L)$ is given by [42]

$$
L=\frac{a_{T}}{\sqrt{2(1-\lambda)+\lambda^{2}}} .
$$

The moiré period for all studied HTS are listed in the last column of Table II. It is seen that for all HTSs (except for GE $/ \mathrm{C}_{3} \mathrm{~N}_{4}$ where $L=129 \AA$ ), the moire period is larger than e.g., the moiré period of $\mathrm{GE} / \mathrm{h}-\mathrm{BN}$, i.e., $130 \AA$ [42].

The most stable configurations of GE $/ \mathrm{C}_{3} \mathrm{~N}, \mathrm{GE} / \mathrm{C}_{3} \mathrm{~N}_{4}$, and $\mathrm{GE} / \mathrm{C}_{4} \mathrm{~N}_{3}$ are found to have $\mathrm{AB}$ stacking while $\mathrm{C}_{3} \mathrm{~N}_{4} / \mathrm{C}_{3} \mathrm{~N}$, $\mathrm{C}_{4} \mathrm{~N}_{3} / \mathrm{C}_{3} \mathrm{~N}$, and $\mathrm{C}_{3} \mathrm{~N}_{4} / \mathrm{C}_{4} \mathrm{~N}_{4}$ have AA-stacking arrangements [see Fig. 1(a)]. The obtained parameters for the lattice constant $(a)$, interlayer distance $\left(z_{\text {eq }}\right)$, and other physical parameters of the HTSs are listed in Table II.

The other possible stackings are shown in Fig. 2. AA and $\mathrm{AB}$ refer to the $\mathrm{AB}$ stacking and $\mathrm{AA}$ stacking. The colored pictures are the most stable HTSs relevant to Fig. 1(a). The ground-state energy $\left(E_{0}\right)$ per area of unit cell for each HTS with respect to the most stable one $\left(E_{n}=E-E_{0}\right)$ is shown in each panel of Fig. 2. Notice that the the most stable HTSs have lower energy (of about $20-70 \mathrm{meV}$ ) than the others.

\section{B. Electronic structure of $\mathrm{GE} / \mathrm{C}_{n} \mathbf{N}_{m}$}

The electronic band structure and corresponding DOS and PDOS of six studied HTSs are shown in Figs. 1(b) and 3, respectively.

The GE $/ \mathrm{C}_{3} \mathrm{~N}$ exhibit metallic characteristics. In comparison to the pristine graphene, the Dirac point shifts below the Fermi level with energy $E_{F}$ about $0.5 \mathrm{eV}$ and is located at the $K$ point. Density of states and PDOS of HTSs are shown in Fig. 3. It is seen that at Fermi level of GE/C ${ }_{3} \mathrm{~N}$, the N/C- $p_{z}$ orbitals of $\mathrm{C}_{3} \mathrm{~N}$ plays the main role in the electronic state, resulting in the metallic behavior.

Interestingly, the system $\mathrm{GE} / \mathrm{C}_{3} \mathrm{~N}_{4}$ is semiconductor with narrow band gap of about $20 \mathrm{meV}$, where the valence band maximum (VBM) and conduction band minimum (CBM) are located at the $K$ point. Moreover, the VBM and CBM of $\mathrm{GE} / \mathrm{C}_{3} \mathrm{~N}_{4}$ are originated from $\mathrm{N}-p_{z}$ and C- $p_{z}$ orbitals and the $\mathrm{N} / \mathrm{C}-p_{z}$ orbitals of $\mathrm{C}_{3} \mathrm{~N}_{4}$, respectively.

The electronic structure of $\mathrm{GE} / \mathrm{C}_{4} \mathrm{~N}_{3}$ reveals a ferromagnetic-metal state where the energy bands are split into $\uparrow$ and $\downarrow$ spin channels. The induced magnetic moment into this system is about $6.85 \mu_{B}$. Note that the magnetic moment of a single layer of $\mathrm{C}_{4} \mathrm{~N}_{3}$ in a 1-unit cell is $1 \mu_{B}$ (see Table I and Supplemental Material SI). Because of the nonzero magnetic moment of bilayer $\mathrm{GE} / \mathrm{C}_{4} \mathrm{~N}_{3}$ and monolayer $\mathrm{C}_{4} \mathrm{~N}_{3}$, we conclude that the magnetism nature of $\mathrm{C}_{4} \mathrm{~N}_{3}$ is preserved when $\mathrm{GE} / \mathrm{C}_{4} \mathrm{~N}_{3}$ bilayer is made. For $\mathrm{GE} / \mathrm{C}_{4} \mathrm{~N}_{3}$, the states around $E_{F}$ mainly originate from C- $p_{z}$ in both $\uparrow$ and $\downarrow$ spin channels and from the $\mathrm{N}-p_{x, y}$ of $\mathrm{C}_{4} \mathrm{~N}_{3}$ in the $\uparrow$ spin channel. The degeneracy of both spin channels are broken, which results in a magnetic moment of about $6.85 \mu_{B}$ per unit cell with $2 \times 2$ supercell of graphene and a unit cell of $\mathrm{C}_{4} \mathrm{~N}_{3}$.

The electronic structure results of the above three HTSs show that the electronic structure of GE is preserved for $\mathrm{GE} / \mathrm{C}_{3} \mathrm{~N}_{4}$, i.e., a linear band structure appears similar to GE. The same effects (minimal change in the band structure) happens when a GE layer is put on top of a h-BN layer [41,43]. However, for the other HTSs, there is a remarkable 

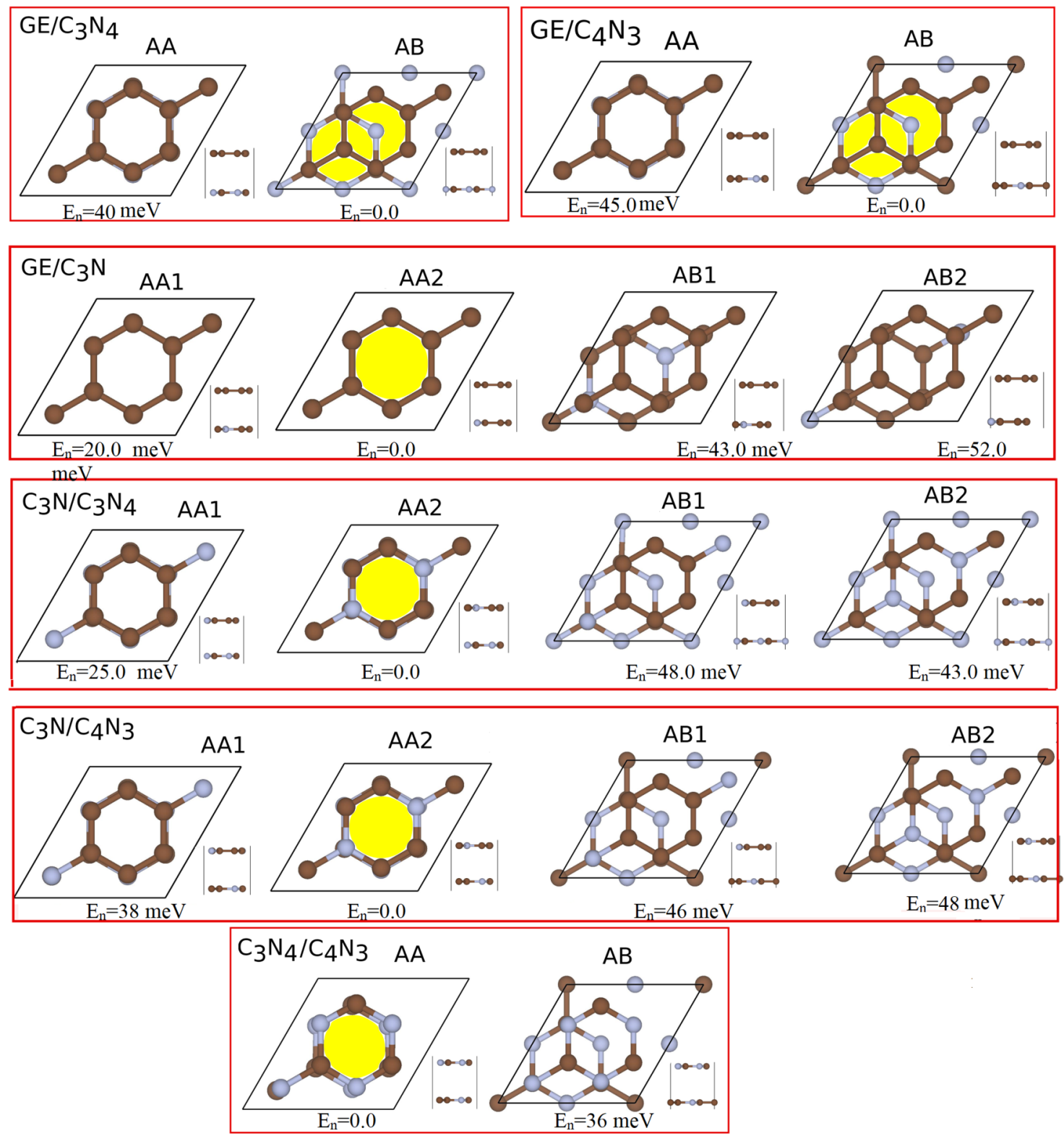

FIG. 2. (Color online.) Schematic illustrations of top and side views for possible stacking of the studied HTSs. The colored pictures are the most stable configurations, where the ground state energy was set to zero, i.e., $E_{0}=0.0$ [see Fig. 1(a)]. Energy per unit cell ( $\left.E_{n}=E-E_{0}\right)$ is given in bottom of each panel.

difference. $[44,45]$. However, for the other HTSs, there is a remarkable difference between the HTS and two corresponding monolayers.

\section{Electronic structure of $\mathbf{C}_{n} \mathbf{N}_{m} / C_{n^{\prime}} \mathbf{N}_{m^{\prime}}$}

The $\mathrm{C}_{3} \mathrm{~N} / \mathrm{C}_{3} \mathrm{~N}_{4}$ is an indirect semiconductor having a band gap of $250 \mathrm{meV}$ where the VBM and CBM are located at $M$ and $\Gamma$ points, respectively. The VBM of GE/ $\mathrm{C}_{3} \mathrm{~N}$ is due to the hybridization of the $\mathrm{N}-p_{z}$ orbitals, while the CBM is formed by the hybridization of $\mathrm{C}-p_{z}$.

The system $\mathrm{C}_{3} \mathrm{~N} / \mathrm{C}_{4} \mathrm{~N}_{3}$ is a ferromagnetic metal and has a magnetic moment of $1.4 \mu_{B}$, which is due to the magnetic properties of $\mathrm{C}_{4} \mathrm{~N}_{3}$. From DOS and PDOS, we see that VBM of $\mathrm{C}_{3} \mathrm{~N} / \mathrm{C}_{3} \mathrm{~N}_{4}$ is due to the hybridization of $\mathrm{N} / \mathrm{C}-p_{z}$ orbitals of $\mathrm{C}_{3} \mathrm{~N}$, while the CBM is due to the hybridization of $\mathrm{C}-p_{z}$ orbitals of $\mathrm{C}_{3} \mathrm{~N}_{4}$.

We found that the system $\mathrm{C}_{3} \mathrm{~N}_{4} / \mathrm{C}_{4} \mathrm{~N}_{3}$ reveals metallic features. Interestingly, the magnetic properties of $\mathrm{C}_{4} \mathrm{~N}_{3}$ is eliminated when it makes a HTS with $\mathrm{C}_{3} \mathrm{~N}_{4}$. This may be due to the AA-stacking form of $\mathrm{C}_{3} \mathrm{~N}_{4} / \mathrm{C}_{4} \mathrm{~N}_{3}$ which results in symmetry of spin-up and spin-down bands. The magnetic properties (asymmetry in spin-up and spin-down channels) of monolayer $\mathrm{C}_{4} \mathrm{~N}_{3}$ is mainly due to the asymmetry in $N-p_{x y}$ orbitals (either for $\mathrm{C}$ atom or in $\mathrm{N}$ ). But the $\mathrm{C}_{3} \mathrm{~N}_{4} / \mathrm{C}_{4} \mathrm{~N}_{3}$ band structure shows that most dominant orbitals are $p_{z}$. On the other hand, because the $\mathrm{vdW}$ interaction between two layers can be affected by this $p_{z}$ orbitals, we expect to see larger effects in the electronic structure of $\mathrm{C}_{3} \mathrm{~N}_{4} / \mathrm{C}_{4} \mathrm{~N}_{3}$ resulting from $p z$ orbitals which are symmetric 


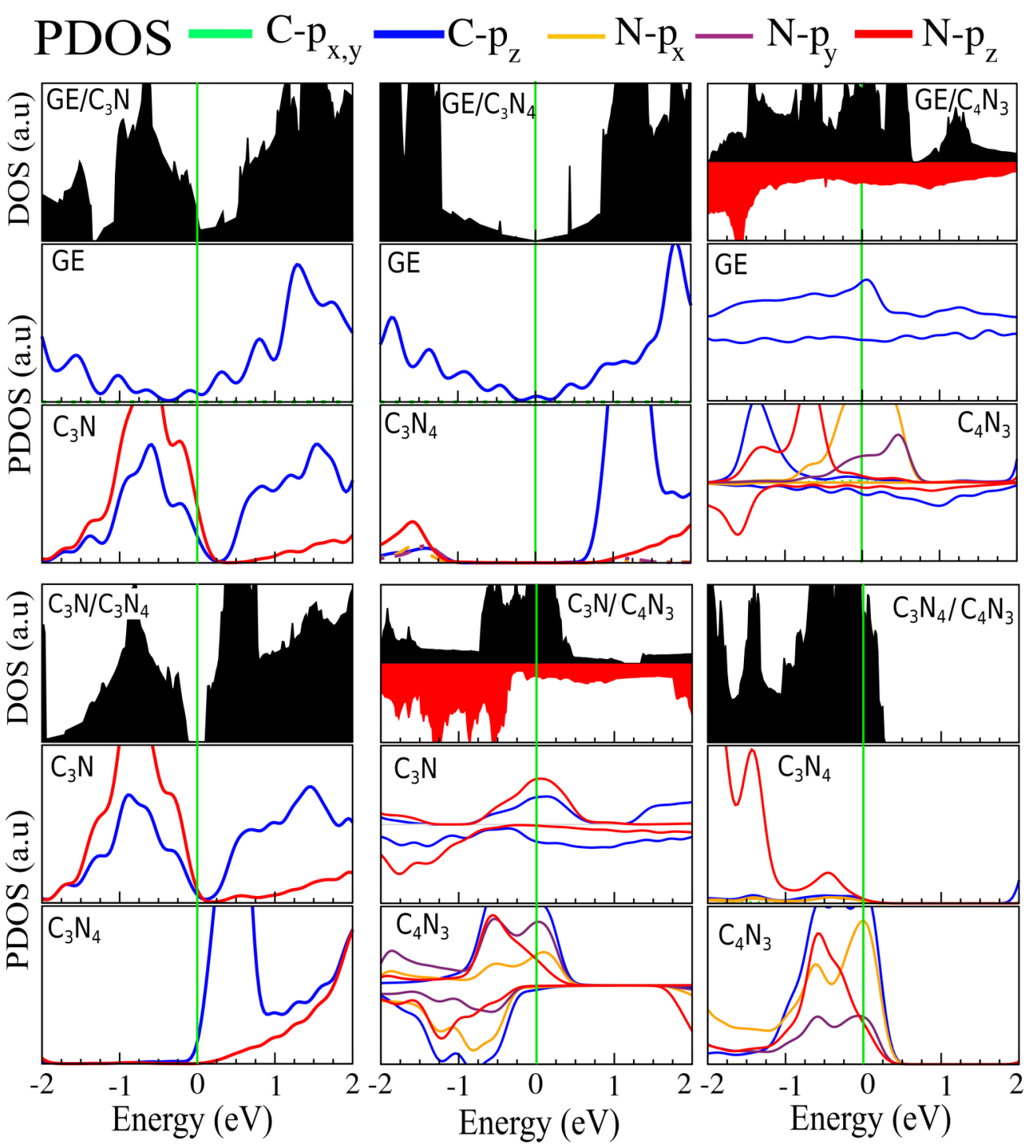

FIG. 3. Density of states and partial density of states of GE/ $\mathrm{C}_{3} \mathrm{~N}, \mathrm{GE} / \mathrm{C}_{3} \mathrm{~N}_{4}, \mathrm{GE} / \mathrm{C}_{4} \mathrm{~N}_{3}, \mathrm{C}_{3} \mathrm{~N}_{4} / \mathrm{C}_{3} \mathrm{~N}, \mathrm{C}_{4} \mathrm{~N}_{3} / \mathrm{C}_{3} \mathrm{~N}$, and $\mathrm{C}_{3} \mathrm{~N}_{4} / \mathrm{C}_{4} \mathrm{~N}_{3}$ heterostructures. The zero energy is set at Fermi level.

in $\mathrm{C}_{4} \mathrm{~N}_{3}$ and $\mathrm{C}_{3} \mathrm{~N}_{4}$ monolayers as well as $\mathrm{C}_{3} \mathrm{~N}_{4} / \mathrm{C}_{4} \mathrm{~N}_{3}$ bilayer.

Our results for $\mathrm{C}_{3} \mathrm{~N} / \mathrm{C}_{4} \mathrm{~N}_{3}$ show that the states around $E_{F}$ mainly originate from the $\mathrm{N}-p_{z}$ of $\mathrm{C}_{3} \mathrm{~N}$ and the $\mathrm{N}-p_{x, y}$ of

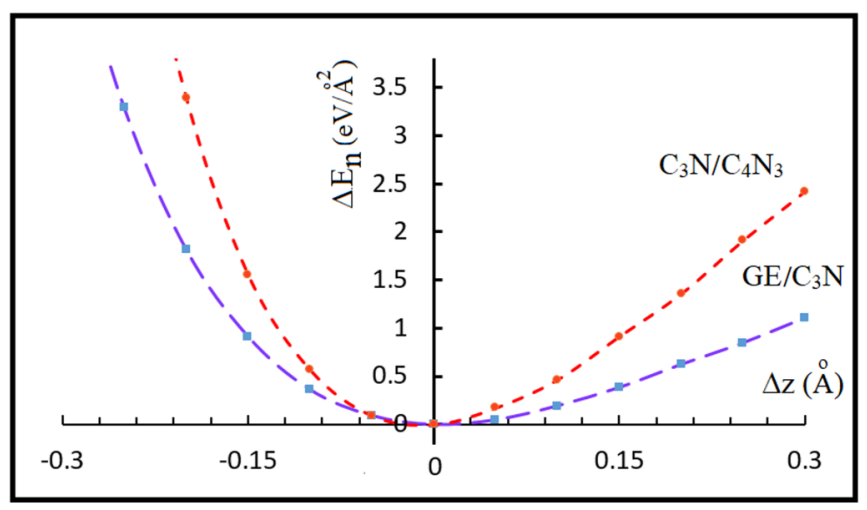

FIG. 4. The relative binding energy with respect to interlayer distance of GE/ $\mathrm{C}_{3} \mathrm{~N}$ and $\mathrm{C}_{3} \mathrm{~N} / \mathrm{C}_{4} \mathrm{~N}_{3}$ HTSs.
$\mathrm{C}_{4} \mathrm{~N}_{3}$. Moreover, in $\mathrm{C}_{3} \mathrm{~N}_{4} / \mathrm{C}_{4} \mathrm{~N}_{3}$, the state at $E_{F}$ belongs to the $\mathrm{N}-p_{x, y}$ and $\mathrm{C}-p_{z}$ orbitals of $\mathrm{C}_{4} \mathrm{~N}_{3}$ yielding the metallic

TABLE III. The lattice constants $a$ and $b$, the magnetic moment per unit cell $\left(M_{\mathrm{tot}}\right)$, and the electronic state of the studied heterojunctions. Different electronic states are labeled as Dirac semi-metal (DSM), half metal (HM), semimetal (SM), ferromagnetic metal (FM), and semiconductor (SC). The band gap $\Delta$ of the systems are shown in the third column listed. The transition of the electronic state (TS) when two individual monolayers are connected laterally to form the corresponding HTJ is indicated by an arrow $(\rightarrow)$.

\begin{tabular}{|c|c|c|c|c|c|}
\hline HTJ & $a(\AA)$ & $b(\AA)$ & $\mathrm{TS}$ & $\Delta(\mathrm{meV})$ & $M_{\mathrm{tot}}$ \\
\hline $\mathrm{GE}-\mathrm{C}_{3} \mathrm{~N}$ & 58 & 4.92 & $(\mathrm{SM}, \mathrm{SC}) \rightarrow \mathrm{SC}$ & $00 \mathrm{meV}$ & 0 \\
\hline $\mathrm{GE}-\mathrm{C}_{3} \mathrm{~N}_{4}$ & 19.59 & 4.89 & $(\mathrm{SM}, \mathrm{SC}) \rightarrow \mathrm{DSM}$ & - & 0 \\
\hline $\mathrm{GE}-\mathrm{C}_{4} \mathrm{~N}_{3}$ & 19.62 & 4.90 & $(\mathrm{SM}, \mathrm{HM}) \rightarrow \mathrm{SC}$ & $100 \mathrm{meV}$ & 0 \\
\hline $\mathrm{C}_{3} \mathrm{~N}-\mathrm{C}_{3} \mathrm{~N}_{4}$ & 19.48 & 4.87 & $(\mathrm{SC}, \mathrm{SC}) \rightarrow \mathrm{SC}$ & $80 \mathrm{mel}$ & 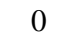 \\
\hline $\mathrm{C}_{3} \mathrm{~N}-\mathrm{C}_{4} \mathrm{~N}_{3}$ & 19.52 & 4.88 & $(\mathrm{SC}, \mathrm{HM}) \rightarrow \mathrm{FM}$ & - & 1.7 \\
\hline $\mathrm{C}_{3} \mathrm{~N}_{4}-\mathrm{C}_{4} \mathrm{~N}_{3}$ & 19.31 & 4.82 & $(\mathrm{SM}, \mathrm{HM}) \rightarrow \mathrm{HM}$ & - & 4 \\
\hline
\end{tabular}


(a)
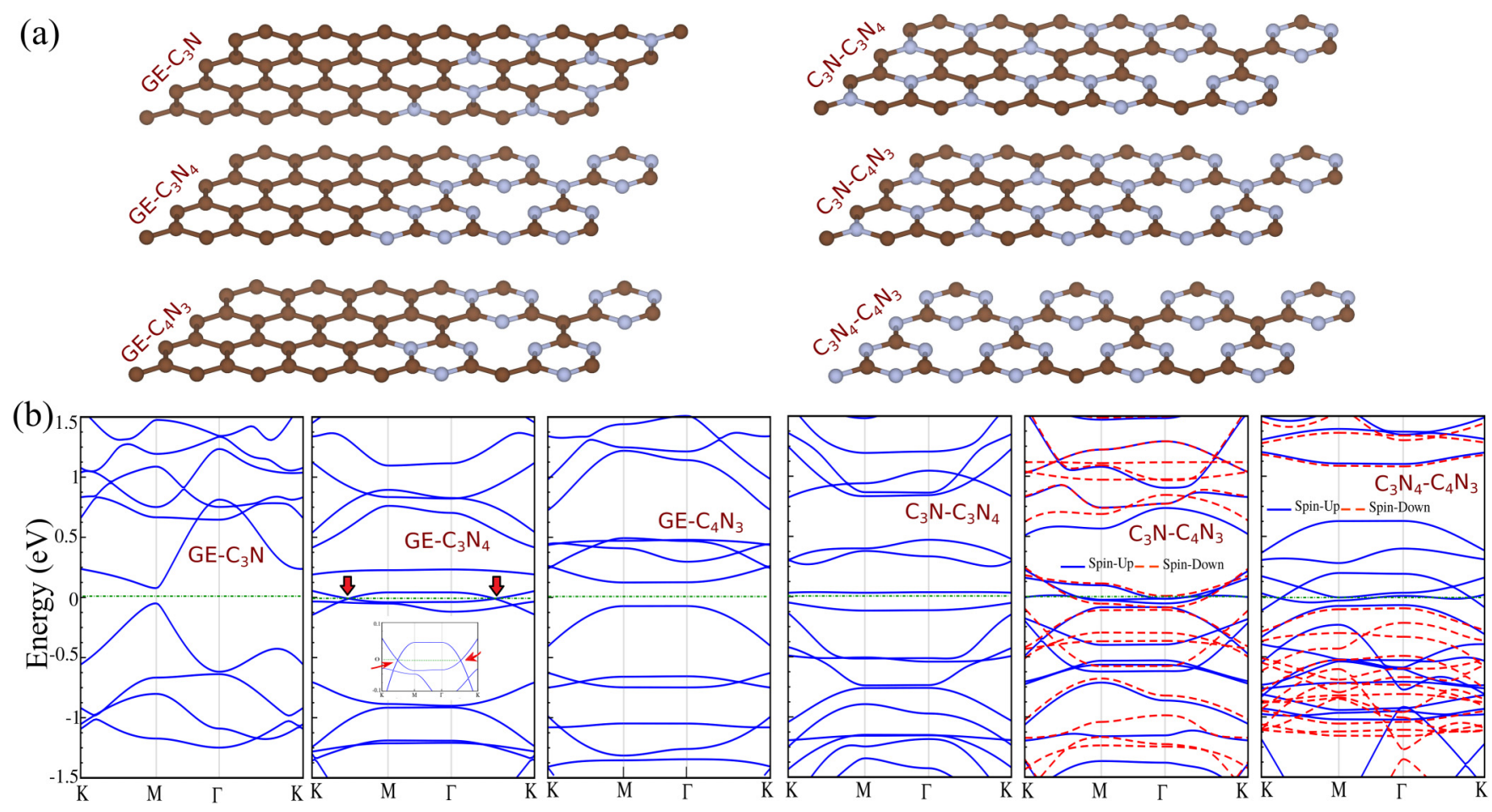

FIG. 5. (a) The optimized atomic structures and the corresponding (b) electronic band structure of GE-C $\mathrm{C}_{3} \mathrm{~N}, \mathrm{GE}-\mathrm{C}_{3} \mathrm{~N}_{4}, \mathrm{GE}_{-} \mathrm{C}_{4} \mathrm{~N}_{3}$, $\mathrm{C}_{3} \mathrm{~N}_{4}-\mathrm{C}_{3} \mathrm{~N}, \mathrm{C}_{4} \mathrm{~N}_{3}-\mathrm{C}_{3} \mathrm{~N}$, and $\mathrm{C}_{3} \mathrm{~N}_{4}-\mathrm{C}_{4} \mathrm{~N}_{3}$ heterojunctions. The brown atoms represent $\mathrm{C}$ and the blue atoms represent $\mathrm{N}$. The zero of energy is set at Fermi level. Two Dirac-like points corresponding to the nodal line feature of $\mathrm{GE}_{-} \mathrm{C}_{3} \mathrm{~N}_{4}$ are shown in the inset and by red arrows.

character. Notice that the initial magnetic feature of $\mathrm{C}_{4} \mathrm{~N}_{3}$ is lost when it is put over $\mathrm{C}_{3} \mathrm{~N}_{4}$.
To show clearly the changes in the electronic band structure of the monolayers when they make HTS, in Fig. S4 of the

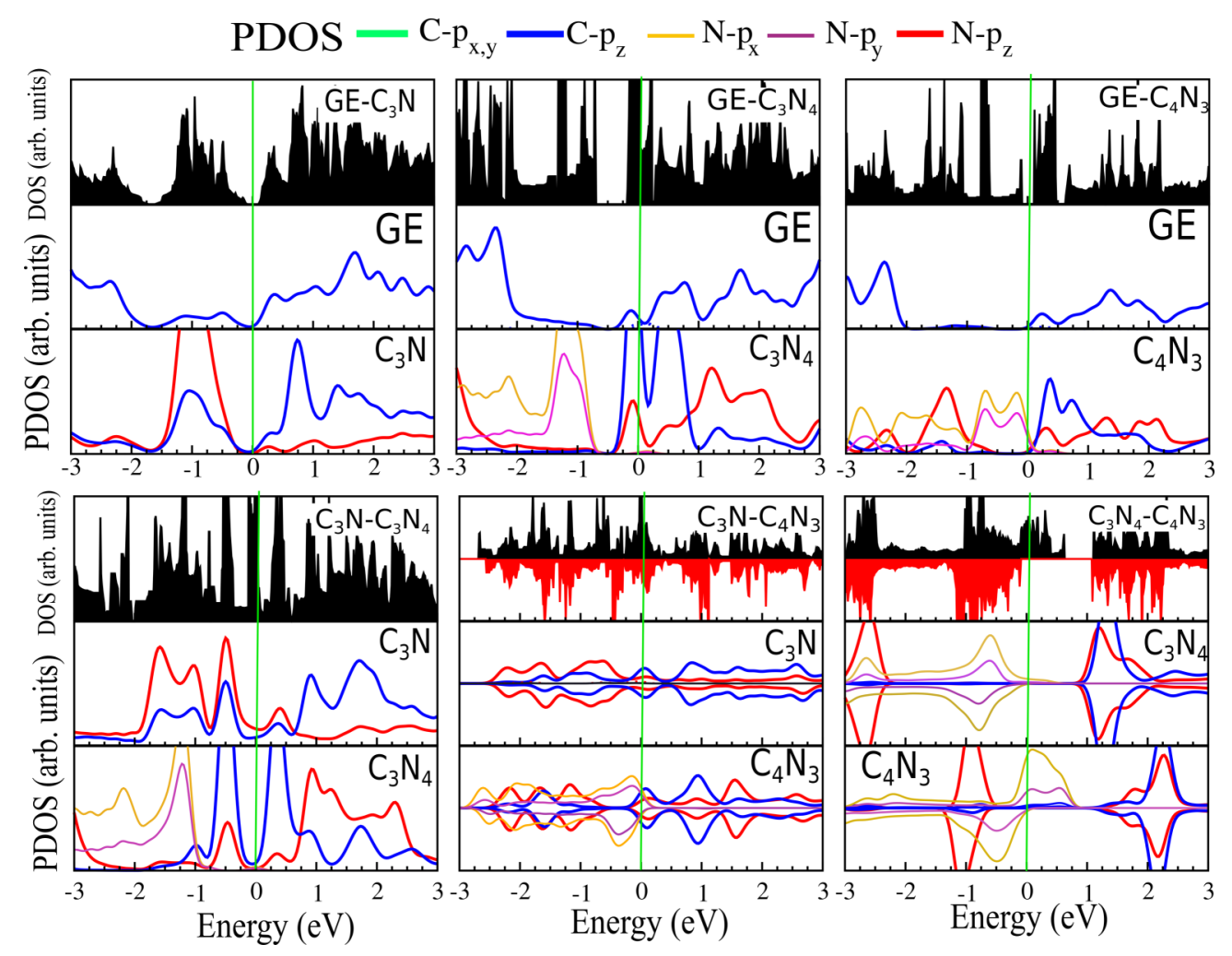

FIG. 6. (Color online.) The density of states and partial density of states of the studied HTJ. 

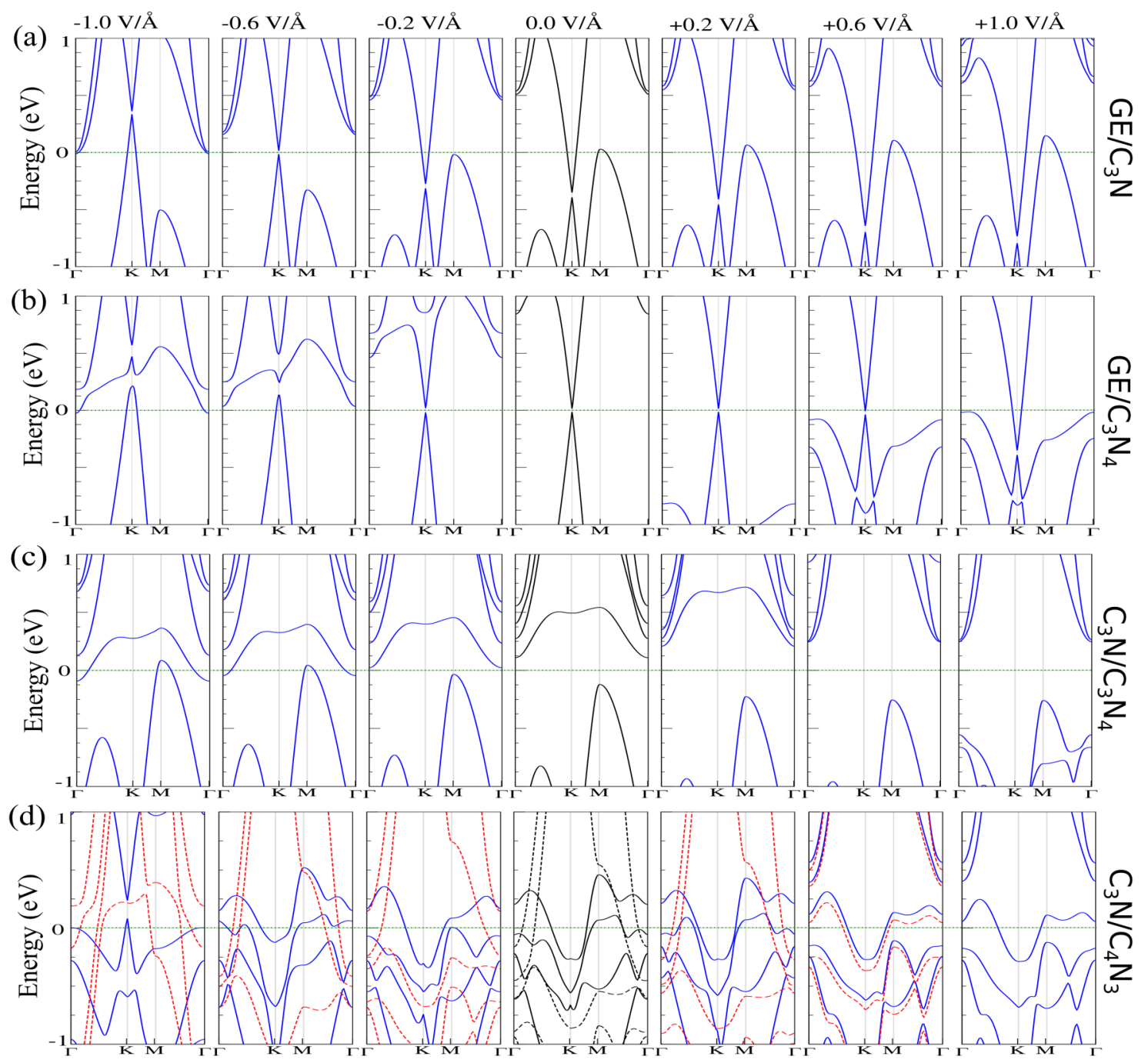

FIG. 7. The electronic band structure of (a) $\mathrm{GE} / \mathrm{C}_{3} \mathrm{~N}$, (b) $\mathrm{GE} / \mathrm{C}_{3} \mathrm{~N}_{4}$, (c) $\mathrm{C}_{3} \mathrm{~N} / \mathrm{C}_{3} \mathrm{~N}_{4}$, and (d) $\mathrm{C}_{3} \mathrm{~N} / \mathrm{C}_{4} \mathrm{~N}_{3}$ heterostructures with respect to the applied an electric field. The positive (negative) electric field denotes parallel (antiparallel) to the $z$ axis. The zero of energy is set at the $E_{F}$.

Supplemental Material we depict the band structure of monolayer and corresponding bilayers.

\section{Binding energy between two layers}

The binding energy stored between the two layers of the HTSs (i.e., the adhesion energy) can be calculated by varying the interlayer distance between two layers. Additional calculations were done to obtain the energy variation for a given interlayer distance. We start from two optimized layers and perform energy calculations. Moving one layer with respect to the other in vertical direction yields binding energy profile. The results for two typical HTSs $\left(\mathrm{GE} / \mathrm{C}_{3} \mathrm{~N}\right.$ and $\mathrm{C}_{3} \mathrm{~N} / \mathrm{C}_{4} \mathrm{~N}_{3}$ ) are shown in Fig. 4. The minimum energy is set to zero, i.e., $\Delta E_{n}=E_{n}(z)-E_{n}\left(z_{\text {eq }}\right)$ and the horizontal axis is shifted by $z_{\text {eq }}$, i.e., $\Delta z=z-z_{\text {eq }}$. The results show that the adhesion between $\mathrm{GE}$ and $\mathrm{C}_{3} \mathrm{~N}$ is stronger than that of between $\mathrm{C}_{3} \mathrm{~N}$ and $\mathrm{C}_{4} \mathrm{~N}_{3}$. Therefore, exfoliating $\mathrm{C}_{n^{\prime}} \mathrm{N}_{m^{\prime}} / \mathrm{C}_{n} \mathrm{~N}_{m}$ would be easier than that of $\mathrm{GE} / \mathrm{C}_{n} \mathrm{~N}_{m}$. As expected, for very large interlayer distances, the pristine graphene properties can be recovered.
The binding energy profile between $\mathrm{GE}$ and $\mathrm{g}-\mathrm{C}_{3} \mathrm{~N}_{4}$ was reported by Li et al. [46].

\section{GE-GCN HETEROJUNCTIONS}

By sticking GCN to GE laterally, we made six HTJs. The optimized atomic structures and corresponding electronic band structures of HTJs are shown in Figs. 4(a) and 4(b). The corresponding lattice parameters and electronic states of each HTJ are listed in Table III.

We found that the $\mathrm{GE}-\mathrm{C}_{3} \mathrm{~N}$ and $\mathrm{GE}-\mathrm{C}_{4} \mathrm{~N}_{3}$ are direct semiconductors with narrow band gaps of $150 \mathrm{meV}$ and $100 \mathrm{eV}$, respectively. By analyzing the charge distribution along the contact line between $\mathrm{GE}$ and $\mathrm{C}_{n} \mathrm{~N}_{m} \mathrm{~s}$, we noticed that there is a minimum change in the charge distribution on the contact line of $\mathrm{GE}-\mathrm{C}_{3} \mathrm{~N}$ (in Fig. S3, we depict valance charge density distribution over the studied HTJs, see Supplemental Material Fig. S3). The semiconducting properties of $\mathrm{GE}-\mathrm{C}_{3} \mathrm{~N}$ and minimal mismatch at the contact line makes GE- $\mathrm{C}_{3} \mathrm{~N}$ an exceptional HTJ that may be realized for potential applications. 


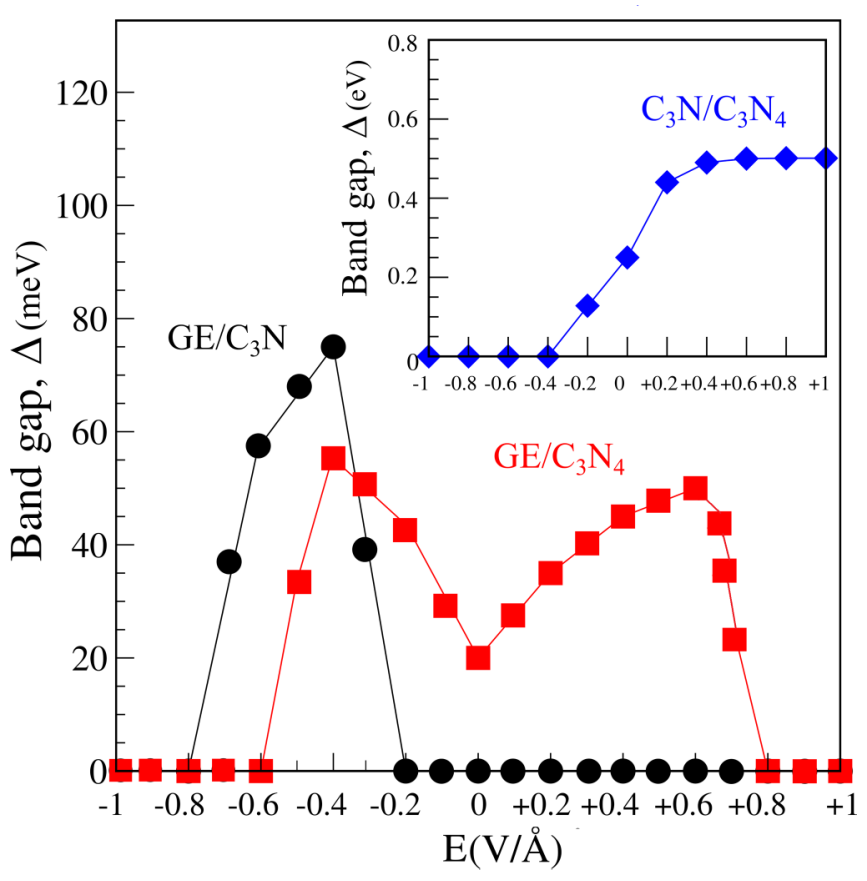

FIG. 8. The variation of band gap with perpendicular electric field for three HTSs.

On the other hand, the electronic structure of GE- $\mathrm{C}_{3} \mathrm{~N}_{4}$ results in a semimetal nodal-line characteristic having a nodal line around the $K$ point. The latter is related to crossing of the energy bands of VBM and CBM at two points along the Fermi level. Generally, in nodal line materials, the Dirac-like crossings along special lines in momentum space create either a closed ring or line of degeneracies, rather than discrete points [see two arrows in Fig. 5(b)]. The appearance of the nodal line in GE- $\mathrm{C}_{3} \mathrm{~N}_{4}$ originates from the $p_{z}$ orbitals of both $\mathrm{C}$ and $\mathrm{N}$ (see Fig. 6). We found semiconducting characteristics with a band gap of $80 \mathrm{meV}$ at the $M$ point for $\mathrm{C}_{3} \mathrm{~N}-\mathrm{C}_{3} \mathrm{~N}_{4}$. Furthermore, $\mathrm{C}_{3} \mathrm{~N}-\mathrm{C}_{4} \mathrm{~N}_{3}$ becomes a ferromagnetic metal having a magnetic moment of $4 \mu_{B}$. The $\mathrm{C}_{3} \mathrm{~N}_{4}-\mathrm{C}_{4} \mathrm{~N}_{3}$ HTJ shows a half-metal characteristic, where only spin-up states crossing the Fermi level and the spin-down channel has band gap. The band split induces a magnetic moment of about $1.7 \mu_{B}$.

From the DOS and PDOS of $\mathrm{C}_{3} \mathrm{~N}-\mathrm{C}_{3} \mathrm{~N}_{4}$ (see Fig. 6), we found that VBM mainly belongs to the $\mathrm{N}-p_{x, y}$ and $\mathrm{N} / \mathrm{C}-p_{z}$ orbitals, while the CBM originates from the C- $p_{z}$ orbitals. The state of $\mathrm{C}_{3} \mathrm{~N}-\mathrm{C}_{4} \mathrm{~N}_{3}$, at $E_{F}$ belongs to the C- $p_{z}$ orbitals in both $\uparrow$ and $\downarrow$ spin channels. The latter confirms the metallic characteristics and also the magnetism nature of the system, which has a magnetic moment of $1.7 \mu_{B}$. Finally, the $\mathrm{C}_{3} \mathrm{~N}_{4}-\mathrm{C}_{4} \mathrm{~N}_{3}$ exhibits half-metal characteristics. The metallic behavior belongs to the $\mathrm{N}-p_{x, y}$ orbitals in $\uparrow$ spin channel.

The summary of the electronic state of the studied HTJ and corresponding transition states are listed in Table II. The results of this section are helpful for designing functional materials such as those proposed recently by Liu et al. [1].

\section{EFFECTS OF PERPENDICULAR ELECTRIC FIELD}

We turn our attention to the effects of perpendicular electric field on the electronic properties of HTSs. The variation of the electronic band structure of four studied HTSs with respect to the electric field $(E)$ is shown in Fig. 7. The positive direction of the electric field is along the $z$ axis, see Fig. 2(a). By calculating the electronic band structure of four HTSs ( $\mathrm{GE} / \mathrm{C}_{3} \mathrm{~N}, \mathrm{GE} / \mathrm{C}_{3} \mathrm{~N}_{4}, \mathrm{C}_{3} \mathrm{~N} / \mathrm{C}_{3} \mathrm{~N}_{4}$, and $\mathrm{C}_{3} \mathrm{~N} / \mathrm{C}_{4} \mathrm{~N}_{3}$ ), different effects are obtained which are as follows:

(1) Although in the absence of electric field $\mathrm{GE} / \mathrm{C}_{3} \mathrm{~N}$ is a metal, it becomes a semiconductor with direct band gap in the presence of electric fields in the range $E=$ $(-0.4,-0.6) \mathrm{V} / \AA$. Interestingly, the metallically of $\mathrm{GE} / \mathrm{C}_{3} \mathrm{~N}$ is preserved in the presence of positive electric fields.

(2) The $\mathrm{GE} / \mathrm{C}_{3} \mathrm{~N}_{4}$ is a direct semiconductor having band gap of $20 \mathrm{meV}$. Our results show that by increasing $|E|$ up to $0.4 \mathrm{~V} / \AA$, the band gap increases almost linearly. The larger $|E|(E>0.6 \mathrm{~V} / \AA$ and $E<-0.4 \mathrm{~V} / \AA)$ causes fast decrease in the band gap, i.e., semiconductor-to-metal transition, see Fig. 8.

(3) The $\mathrm{C}_{3} \mathrm{~N} / \mathrm{C}_{3} \mathrm{~N}_{4}$ exhibit a indirect semiconductor with band gap of $250 \mathrm{meV}$ when $E=0$, but its band gap increases up to $450 \mathrm{meV}$ when $E=0.4 \mathrm{~V} / \AA$ and remains constant beyond that. Surprisingly, by reversing the electric fields direction completely different behavior happens, i.e., the band gap decreases to $60 \mathrm{meV}$ when $E=-0.2 \mathrm{~V} / \AA$ and approaches zero beyond $E=-0.4 \mathrm{~V} / \AA$. Therefore, for the electric fields $E<-0.4 \mathrm{~V} / \AA$, i.e. a semiconductor-to-metal transition occurs, see the inset in Fig. 8.

(4) The $\mathrm{C}_{3} \mathrm{~N} / \mathrm{C}_{4} \mathrm{~N}_{3}$ is a metal with nonmagnetic ground state when $E=0$. The metallicity is preserved for the electric fields between +0.2 and $+0.8 \mathrm{~V} / \AA$. Under the field $E=$ $+1 \mathrm{~V} / \AA$, a metal to ferromagnetic-metal transition occurs and the system gains a magnetic moment of $0.3 \mu_{B}$.

(5) We found an electronic state transition in the band structure of $\mathrm{C}_{3} \mathrm{~N} / \mathrm{C}_{4} \mathrm{~N}_{3}$ (metal to ferromagnetic metal) for the electric fields in the range $-0.4 \mathrm{~V} / \AA$ and $-0.6 \mathrm{~V} / \AA$, together gaining a magnetic moments of 0.8 and $1.9 \mu_{B}$, respectively. Also it becomes a half metal when $E=-0.8 \mathrm{~V} / \AA$, having a magnetic moment of $5 \mu_{B}$ and Dirac half metal when $\mathrm{E}=$ $-1.0 \mathrm{~V} / \AA$ with a magnetic moment of $3 \mu_{B}$.

\section{SUMMARY AND DISCUSSION}

In summary, we systematically studied the structural and electronic properties of HTSs made of graphene and three graphitic carbon nitrides, i.e., $\mathrm{C}_{3} \mathrm{~N}, \mathrm{C}_{3} \mathrm{~N}_{4}$, and $\mathrm{C}_{4} \mathrm{~N}_{3}$. We found that $\mathrm{C}_{3} \mathrm{~N}, \mathrm{C}_{3} \mathrm{~N}_{4}$ with planar structures are semiconductors while $\mathrm{C}_{4} \mathrm{~N}_{3}$ exhibits half-metallic features with significant DOS at Fermi level. The half metallicity originates mainly from the $p_{x, y}$ planar orbitals of $\mathrm{N}$ atoms in $\mathrm{C}_{4} \mathrm{~N}_{3}$ monolayer. We found that the hybridized systems made of $\mathrm{C}_{4} \mathrm{~N}_{3}$ and $\mathrm{GE}$ or $\mathrm{C}_{3} \mathrm{~N}$ are ferromagnetic HTSs, while the bilayer made of $\mathrm{C}_{4} \mathrm{~N}_{3}$ and $\mathrm{C}_{3} \mathrm{~N}_{4}$ is metal.

For the $\mathrm{GE}-\mathrm{C}_{3} \mathrm{~N}_{4} \mathrm{HTJ}$, we found a nodal line feature which originates from the $p_{z}$ orbitals of both $\mathrm{C}$ and $\mathrm{N}$. Also, we found that $\mathrm{C}_{3} \mathrm{~N}_{4}-\mathrm{C}_{4} \mathrm{~N}_{3}$ and $\mathrm{C}_{3} \mathrm{~N}-\mathrm{C}_{4} \mathrm{~N}_{3}$ systems have nonzero magnetic moments with half-metallicity and ferromagneticmetal characteristics, respectively. We also found that there is a minimum change in the charge distribution on the contact line of $\mathrm{GE}-\mathrm{C}_{3} \mathrm{~N}$. The valance charge distribution and the degree of porosity and its (the hollow sites in GCN) 
in $\mathrm{C}_{3} \mathrm{~N}_{4}$ and $\mathrm{C}_{3} \mathrm{~N}_{4}$ significantly influence the electronic structure of GCN monolayers and corresponding HTSs and HTJs.

The electronic properties of the vdW HTSs were modulated by applying a perpendicular electric field. We found that in the presence of an electric field which is directed from GE to $\mathrm{C}_{3} \mathrm{~N}$, i.e., $E \geqslant 0$, there is no band gap in the $\mathrm{GE} / \mathrm{C}_{3} \mathrm{~N}$ but by reversing the direction of electric field for $E<-0.2 \mathrm{~V} / \AA$, a band gap of about $40 \mathrm{meV}$ is opened. Moreover, other similar asymmetrical effects were obtained for $\mathrm{C}_{3} \mathrm{~N} / \mathrm{C}_{3} \mathrm{~N}_{4}$.
These asymmetrical effects cannot happen either in bilayer graphene (where only a band gap of $100 \mathrm{meV}$ can be induced in the system independent of the direction of applied electric field) or in $\mathrm{GE} / \mathrm{g}-\mathrm{C}_{3} \mathrm{~N}_{4}$ [46]. Depending on the direction of the applied electric field, these two HTSs show a metallic or semiconducting behavior. This might be promising for the realization of new HTSs that have electrically tunable band gaps and unusual responses to the applied electric field. This phenomena is of great significance for both basic physics and applications.
[1] X. Liu and M. C. Hersam, Sci. Adv. 5, 6444 (2019).

[2] Y. Zheng, J. Liu, J. Liang, M. Jaroniec, and S. Qiao, Energy Environ. Sci. 5, 6717 (2012).

[3] J. Mahmood, E. K. Lee, M. Jung, D. Shin, I.-Y. Jeon, S.-M. Jung, H.-J. Choi, J.-M. Seo, S.-Y. Bae, S.-D. Sohn, N. Park, J. H. Oh, H.-J. Shin, and J.-B. Baek, Nat. Commun. 6, 6486 (2015).

[4] B. Mortazavi, Carbon 118, 25 (2017).

[5] M. B. Tagani and S. I. Vishkayi, J. Appl. Phys. 124, 8 (2018).

[6] G. Zhu, K. Lü, Q. Sun, Y. Kawazoe, and P. Jena, Comput. Mater. Sci. 81, 275 (2014).

[7] X. Li, Sh. Zhang, and Q. Wang, Phys. Chem. Chem. Phys. 15, 7142 (2013).

[8] A. J. Mannix, B. Kiraly, M. C. Hersam, and N. P. Guisinger, Nat. Rev. Chem. 1, 0014 (2017).

[9] A. Du, S. Sanvito, and S. C. Smith, Phys. Rev. Lett. 108, 197207 (2012).

[10] L. Britnell, R. M. Ribeiro, A. Eckmann, R. Jalil, B. D. Belle, A. Mishchenko, Y.-J. Kim, R. V. Gorbachev, T. Georgiou, S. V. Morozov, A. N. Grigorenko, A. K. Geim, C. Casiraghi, A. H. C. Neto, and K. S. Novoselov, Science 340, 1311 (2013).

[11] H. Tian, Zh. Tan, C. Wu, X. Wang, M. A. Mohammad, D. Xie, Y. Yang, J. Wang, L.-J. Li, J. Xu, and T.-L. Ren, Sci. Rep. 4, 5951 (2014).

[12] S. K. Singh, M. Neek-Amal, S. Costamagna, and F. M. Peeters, Phys. Rev. B 91, 014101 (2014).

[13] C. R. Dean, A. F. Young, I. Meric, C. Lee, L. Wang, S. Sorgenfrei, K. Watanabe, T. Taniguchi, P. Kim, K. L. Shepard, and J. Hone, Nat. Nanotech. 5, 722 (2010).

[14] X. Lin, Y. Xu, A. A. Hakro, T. Hasan, R. Hao, B. Zhang, and H. Chen, J. Mater. Chem. C 1, 1618 (2013).

[15] J. Xue, J. Sanchez-Yamagishi, D. Bulmash, Ph. Jacquod, A. Deshpande, K. Watanabe, T. Taniguchi, P. Jarillo-Herrero, and B. J. LeRoy, Nat. Mater. 10, 282 (2011).

[16] M. Neek-Amal, A. Sadeghi, G. R. Berdiyorov, and F. M. Peeters, Appl. Phys. Lett. 103, 261904 (2013).

[17] Y. Cai, Ch.-P. Chuu, C. M. Wei, and M. Y. Chou, Phys. Rev. B 88, 245408 (2013).

[18] Y. Sun, C. Li, Y. Xu, H. Bai, Z. Yao, and G. Shi, Chem. Commun. 46, 4740 (2010).

[19] W. Hu, T. Wang, and J. Yang, J. Mater. Chem. C 3, 4756 (2015).

[20] J. Wang, Zh. Guan, J. Huang, Q. Li, and J. Yang, J. Mater. Chem. A 2, 7960 (2014).

[21] S. Ali Ansari, M. O. Ansari, and M. Hwan Cho, Sci. Rep. 6, 27713 (2016)
[22] A. Hashmi and J. Hong, Sci. Rep. 4, 4374 (2014).

[23] A. Bafekry, S. Farjami Shayesteh, and F. M. Peeters, Phys. Chem. C 123, 12485 (2019).

[24] A. Bafekry, M. Ghergherehchi, and S. Farjami Shayesteh, Phys. Chem. Chem. Phys. 21, 10552 (2019).

[25] A. Bafekry, C. Stampfl, S. Farjami Shayesteh, and F. M. Peeters, Adv. Elec. Mater. 5, 1900459 (2019).

[26] A. Bafekry, S. Farjami Shayesteh, and F. M. Peeters, Phys. Chem. Chem. Phys. 21, 21070 (2019).

[27] Sh. Guan, Y. Cheng, Ch. Liu, J. Han, Y. Lu, A. Y. Shengyuan, and Y. Yao, Appl. Phys. Lett. 107, 231904 (2015).

[28] A. Bafekry, M. Ghergherehchi, S. Farjami Shayesteh, and F. M. Peeters, Appl. Phys. 126, 144304 (2019).

[29] A. Bafekry, B. Mortazavi, and S. Farjami Shayesteh, J. Magn. Magn. Mater., 491, 165565 (2019).

[30] S. K. Singh, M. Neek-Amal, and F. M. Peeters, J. Chem. Phys. 140, 074304 (2014).

[31] M. Neek-Amal, J. Beheshtian, A. Sadeghi, K. H. Michel, and F. M. Peeters, J. Phys. Chem. C 117, 13261 (2013).

[32] J. Beheshtian, A. Sadeghi, M. Neek-Amal, K. H. Michel, and F. M. Peeters, Phys. Rev. B 86, 195433 (2012).

[33] A. Bafekry, C. Stampfl, M. Ghergherehchi, S. Farjami Shayesteh, Carbon 157, 371 (2020).

[34] A. Bafekry, B. Akgenc, S. F. Shayesteh, B. Mortazavi, Appl. Surf. Sci. 505, 144450 (2020).

[35] J. P. Perdew, K. Burke, and M. Ernzerhof, Phys. Rev. Lett. 77, 3865 (1996).

[36] T. Ozaki, Phys. Rev. B 67, 155108 (2003).

[37] N. Troullier and J. L. Martins, Phys. Rev. B 43, 1993 (1991).

[38] T. Ozaki and H. Kino, Phys. Rev. B 69, 195113 (2004).

[39] H. J. Monkhorst and J. D. Pack, Phys. Rev. B 13, 5188 (1976).

[40] T. Bučko, J. Hafner, S. Lebègue, and J. G. Angyán, J. Phys. Chem. A 114, 11814 (2010).

[41] See Supplemental Material at http://link.aps.org/supplemental/ 10.1103/PhysRevB.101.085417 for more details about structural and electronic properties of single layer of graphenegraphitic carbon nitride, which includes Refs. [7,22,43,46-54].

[42] M. Neek-Amal and F. M. Peeters, Appl. Phys. Lett. 104, 041909 (2014).

[43] A. K. Geim and K. S. Novoselov, Nat. Mater. 6, 183 (2007).

[44] J. D. Correa and E. Cisternas, Solid State Commun. 241, 1 (2016).

[45] K. Zollner, M. Gmitra, and J. Fabian, Phys. Rev. B 99, 125151 (2019). 
[46] X. Li, Y. Dai, Y. Ma, S. Hana, and B. Huanga, Phys. Chem. Chem. Phys. 16, 4230 (2014).

[47] J. Mahmood, E. K. Lee, M. Jung, D. Shin, H.-J. Choi, J.-M. Seo, S.-M. Jung, D. Kim, F. Li, M. S. Lah, N. Park, H.-J. Shin, J. H. Oh, and J.-B. Baek, Proc. Natl. Acad. Sci. USA, 113, 7414 (2016).

[48] S. Mizuno and M. Fujita, and K. Nakao, Synth. Met. 71, 1869 (1995).

[49] E. Kroke, M. Schwarz, E. Horath-Bordon, P. Kroll, B. Noll, and A. D. Norman, Sci. Rep. 4, 4374 (2015).

[50] X. Zhang, M. Zhao, A. Wang, X. Wang, and A. Du, J. Mater. Chem. C 1, 6265 (2013).
[51] H. Wu, Y. Liu, E. Kan, Y. Ma, W. Xu, J. Li, M. Yan, R. Lu, J. Wei, and Y. Qian, J. Phys. D: Appl. Phys. 49, 295301 (2016).

[52] P. Giannozzi, S. Baroni, N. Bonini, M. Calandra, R. Car, C. Cavazzoni, D. Ceresoli, G. L. Chiarotti, M. Cococcioni, I. Dabo et al., J. Phys.: Condens. Matter 21, 395502 (2009).

[53] Q. Hu, Q. Wu, H. Wang, J. He, and G. Zhang, Phys. Status Solidi B 249, 784 (2011).

[54] H. J. Xiang, B. Huang, Z. Y. Li, S.-H. Wei, J. L. Yang, and X. G. Gong, Phys. Rev. X 2, 011003 (2012). 